\title{
The Neuroprotective Actions of a Calcium Channel Antagonist, Flunarizine, in the Infant Rat
}

\author{
A. J. GUNN, T. MYDLAR, L. BENNET, R. L. M. FAUlL, S. GORTER, C. COOK, \\ B. M. JOHNSTON, AND P. D. GLUCKMAN \\ Developmental Physiology Laboratory, Department of Paediatrics, University of Auckland, \\ Auckland, New Zealand
}

\begin{abstract}
One postulated final common pathway leading to neuronal death after hypoxic-ischemic insults is an increase in intracellular calcium concentrations. We examined the effect of pretreatment with flunarizine, a calcium channel antagonist known to pass the blood brain barrier, on the behavioral and histologic changes after an hypoxic-ischemic insult in the infant rat. The 21-d-old rats were subjected to unilateral carotid ligation, then to $2 \mathrm{~h}$ of hypoxia. They were pretreated with either flunarizine (30 $\mathrm{mg} / \mathrm{kg}$, intraperitoneally) or with an equal volume of diluent. After 5 days of observation they were killed for histology. Acute behavioral abnormalities were observed in more controls than treatment animals, 52 vs $11 \%(p<$ 0.002 ). Cerebral injury was almost entirely confined to the ligated side and was significantly worse in the control rats. Full thickness cortical infarction was noted in $56 \%$ of controls $(n=27)$ vs $4 \%$ of flunarizine-treated rats $(n=$ $24),(p<0.001)$. Mean and maximum damage scores for all areas assessed including cortex, corpus striatum, thalamus, amygdala, and hippocampus were improved markedly in treatment rats $(p<0.005)$. These observations confirm that flunarizine, when given prophylactically, has a neuroprotective effect against hypoxic-ischemic injury in the developing brain. (Pediatr Res 25:573-576).
\end{abstract}

Perinatal hypoxic-ischemic encephalopathy is associated with a significant mortality and increased risk of cerebral palsy (1). The majority of cases appear to be due to antepartum or intrapartum insults (2). Recently attention has focused on the role of intracellular calcium accumulation as one common mechanism by which asphyxia leads to neuronal death $(3,4)$. Agents that inhibit calcium flux may therefore be neuroprotective. Although many studies have examined this hypothesis in adult species (519 ), only two previous studies have examined the protective effect of calcium antagonists in immature animals $(20,21)$. We studied the behavioral and histologic outcome in infant rats using a model of unilateral carotid ligation followed by hypoxia, originally developed by Levine (22) with some later modifications (23), and investigated the protective effects of a calcium channel antagonist, flunarizine. After a pilot study a larger study was performed using more sensitive histopathologic procedures.

Received October 24, 1988; accepted January 19, 1989.

Correspondence and reprint requests Prof P. D. Gluckman, Developmental Physiology Laboratory, Department of Paediatrics, University of Auckland, Private Bag, Auckland, New Zealand.

Supported by grants from the Medical Research Council of New Zealand, the Neurological Foundation and the Foundation for the Newborn and the National Childrens Health Research Foundation.

\section{MATERIALS AND METHODS}

Experimental preparation. The 21-d-old Wistar rats were anaesthetised with a $2 \%$ halothane $/ 0_{2}$ mixture. In each rat one carotid artery was exposed and ligated with 6.0 silk sutures. The rats were removed from anaesthesia and then received, by intraperitoneal injection, either flunarizine (Janssen Pharmaceutica, Beerse, Belgium), $30 \mathrm{mg} / \mathrm{kg}$ or an equal volume of the diluent, $10 \%$ ethanol, $1.5 \mathrm{ml} / \mathrm{kg}$, given in equally divided doses. The first dose was given immediately after surgery, the second immediately before the hypoxia, $2 \mathrm{~h}$ later.

Each rat was next subjected to an hypoxic environment of $8 \%$ $\mathrm{O}_{2}$ and $2 \% \mathrm{CO}_{2}$ [to prevent hypocapnia induced vasospasm (24)], maintained at $37^{\circ} \mathrm{C}$, for $120 \mathrm{~min}$. The pups were then returned to their cages, with their litter mates. Daily after the hypoxia each rat was behaviorally tested by a blind, independent observer (LB), who scored each for the presence of five possible abnormalities: fits, absence of startle response, abnormal turning, impaired righting, and impaired response to tail pinch $(23,25)$. On the day of death a further scoring for residual abnormalities was made. The presence of definite unilateral weakness was scored as 2 , whereas other behavioral problems such as excessive or reduced activity or persistent piloerection were scored as 1 . Death was by the injection of pentobarbital. These experiments were approved by the Animal Ethical Committee of the University of Auckland.

Pilot study. This study included the two main groups. 1) Flunarizine pretreated, with ligation and hypoxia, the treatment group $(n=5) .2)$ Ethanol pretreated, with ligation and hypoxia, the control group $(n=9)$. Four groups of sham animals were also studied. 1) Flunarizine, with hypoxia, but sham ligation ( $n$ $=5) ; 2$ ) ethanol, with hypoxia, but sham ligation $(n=9) ; 3)$ ethanol, no hypoxia, with ligation $(n=4) ; 4)$ ethanol, no hypoxia, sham ligation $(n=5)$.

Behavioral testing was performed for 10 days. The brains were snap frozen after death on dry ice. Coronal sections were cut at $40 \mu \mathrm{M}$ and every fourth section stained with cresyl violet. Hemispheric diameter was compared between the ligated and the unligated side at the level of the anterior commissure, and the larger of the two sides noted. Neuronal density in a randomly selected area of the corpus striatum $\left(1.638 \times 10^{-8} \mathrm{M}^{2}\right)$ in 5 to 10 sections per brain was calculated. Each neuron was counted as undamaged only if the cell structure was entirely intact.

Main study. Flunarizine pretreated $(n=32)$ and $10 \%$ ethanol pretreated $(n=40)$ groups of infant rats, subject to the Levine procedure as above, were compared.

Each rat was behaviorally tested daily for 5 days after the hypoxia for the five possible abnormalities. At death the brains were perfused through the left cardiac ventricle with normal saline followed by $10 \%$ Formaldehyde then $10 \%$ Formaldehyde/ $10 \%$ sucrose. The brains were embedded in paraffin, coronally 
subserially sectioned to $10 \mu \mathrm{M}$, and then stained with thionin/ acid fuchsin (26). Each section was examined by light microscopy. The presence or absence of full thickness cerebral infarction was noted at low power $(25 \times)$, then each region was assessed under a magnification of $400 \times$. Neurones with ischemic cell change as described by Brown and Brierley (27), with acidophilic (red) cytoplasm and contracted nuclei or with just a thin rim of red cytoplasm with pyknotic nuclei were assessed as dead whereas all others were considered viable $(26,27)$. Each region was scored for the proportion of dead neurones. The average value from four sections was used in all cases except for the lateral frontoparietal cortex where the average of four areas per section and four sections, spaced from anterior to posterior, were used. The damage scores were as follows: $0=$ no dead neurones, $1=>0$ $25 \%, 2=>25-50 \%, 3=>50-75 \%, 4=>75-100 \%$ of neurones were dead.

Data analysis. Damage and behavioral scores were analyzed by two-way analysis of variance for litter and treatment group. $t$ tests were performed to test differences between subgroups. Survival, the incidence of behavioral problems and of cerebral infarction were examined by $\chi^{2}$ test, except when the numbers were low, where Fishers exact test was used. All values are expressed as mean $\pm \mathrm{SD}$.

\section{RESULTS}

Pilot Study. Behavioral testing. No sham controls $(n=23)$ or flunarizine rats $(n=5)$ had acute behavioral changes whereas eight of nine true controls (subject to hypoxia and ligation) showed significant abnormalities $(p<0.01)$. A consistent pattern was seen of acute disturbances that were worse in the $24 \mathrm{~h}$ after the insult and gradually resolving over 2 to 3 days with only mild unilateral weakness still apparent by 10 days.

Histology. Hemispheric size was symmetrical in all flunarizinetreated $(n=4)$ and sham rats $(n=20)$ but in six of eight control rats the hemisphere on the ligated sided was smaller $(p<0.05)$. The density of intact neurons in the corpus striatum was markedly reduced on the ligated side vs the nonligated side $(1.34 \pm$ 0.76 vs $2.29 \pm 0.91, \times 10^{8}$ neurons $\left./ \mathrm{M}^{2}\right)$ in the controls $(n=8, p$ $<0.005)$ but not in the flunarizine treated animals $(n=4$, NS), $\left(1.92 \pm 0.61\right.$ vs $2.04 \pm 0.70, \times 10^{8}$ neurons $\left./ \mathrm{M}^{2}\right)$ or in eight sham animals.

Main Study. A total of $77.5 \%$ of controls $(n=40)$ and $84 \%$ of flunarizine $(n=32)$ pretreated rats survived (NS). The majority of those who died did so during the hypoxia, and there were no deaths more than $12 \mathrm{~h}$ after cessation of the hypoxia.

Behavioral testing. The same pattern of acute and residual abnormalities was seen as in the pilot study. Acute problems included both generalized fits and focal motor convulsions with secondary generalization. The righting response was frequently absent or greatly slowed, although many circled repeatedly in one direction, usually away from the side of ligation although a few had an increased tendency to turn in that direction. Only one (control) animal showed an abnormal startle response and all respondect to a tail pinch. Acute motor problems were less frequent $(p<0.002)$ in flunarizine pretreated animals $(11 \%, n$ $=27$ ) than in control animals $(51.6 \%, n=31)$. These resolved progressively and persisted at 5 days in only one control rat. As is shown in Figure 1 the mean duration of each of the three motor problems: fitting, abnormal circling, and impaired righting, was reduced in the flunarizine rats $(p<0.005)$.

Once the acute disturbance had resolved, residual deficits were more frequent in controls than flunarizine-treated animals. A total of $42 \%$ of controls vs $4 \%$ of flunarizine rats showed a unilateral palsy contralateral to the ligation $(p<0.001)$; other problems were infrequent. The acute and residual scores were highly intercorrelated $\left(r^{2}=0.69, p<0.00001\right)$.

Histology. Cerebral injury ranged from no damage, to laminar loss in layer 3 of the lateral cortex or selective loss in the CA1/2 region of the hippocampus, through to gross infarction. Only $4 \%$
( $n=27)$ controls vs $29 \%(n=24)$ flunarizine animals had absolutely no dead neurons in any section examined $(p<0.02)$. When rats with less than $5 \%$ neuronal death in at most two regions were considered with the normals as having trivial damage the difference is striking: $11 \%$ of controls vs $58 \%$ of flunarizine rats $(p<0.001)$ had trivial damage.

Full thickness infarction of the cerebral cortex was much more frequent in controls $(55.5 \%)$ than in flunarizine pretreated rats $(4 \%, p<0.001)$. The mean damage scores were significantly less in the flunarizine-pretreated pups in every region examined (Fig. 2 ), with the reduction in damage varying by $>80 \%$ in the cortex $(p<0.0001)$ and by $>50 \%$ in the CA $1 / 2$ region of the hippocampus $(p<0.006)$. The lesser degree of improvement in hippocampal scores compared with cortex or striatum was significant $(p<0.01)$. Although ischemic damage was documented

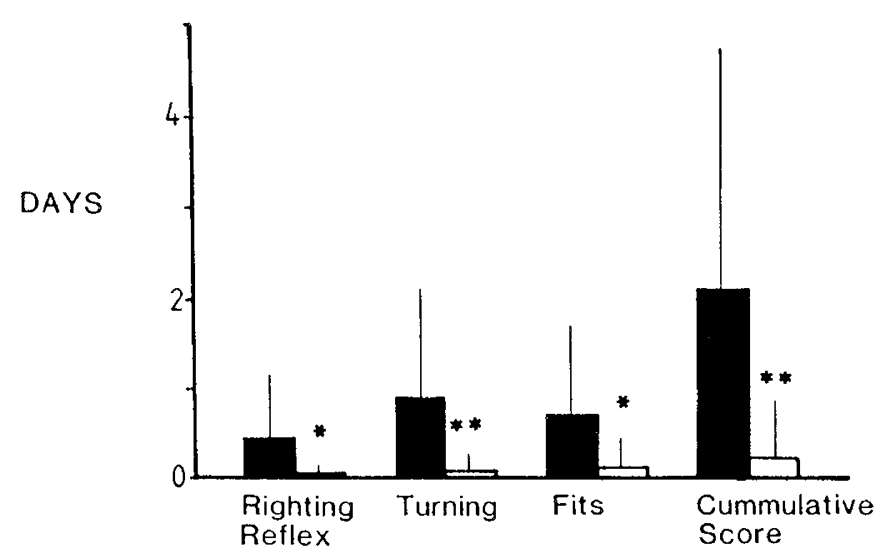

Fig. 1. Number of days each motor abnormality was observed (mean $\pm \mathrm{SD})$ in controls $(n=40$, black bars) and flunarizine pretreated rats ( $n$ $=32$, open bars). ${ }^{*} p<0.05,{ }^{* *} p<0.005$.

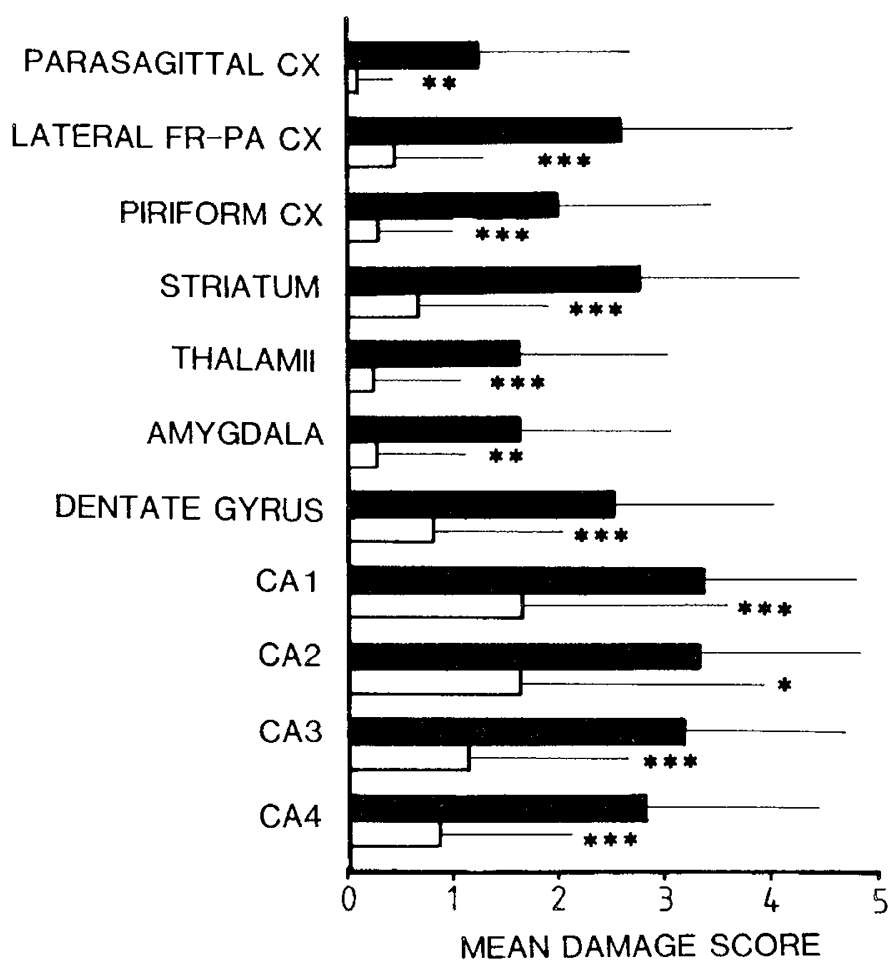

Fig. 2. Mean damage scores (mean \pm SD) for different cerebral regions comparing controls ( $n=31$, black bars), and flunarizine pretreated 21-d-old rats $\left(n=27\right.$, open bars). ${ }^{*} p<0.01,{ }^{* *} p<0.005,{ }^{* * *} p$ $<0.001$. FR- $P A$, fronto-parietal cortex; CA1-4 are regions of the hippocampus. 
primarily ipsilateral to the ligation, eight rats had minor (grade 1 or 2) damage on the unligated side: $26 \%$ of controls vs $4 \%$ flunarizine rats $(p<0.05)$. Of these, the majority $(6 / 8)$ had CAl/ 2 lesions.

\section{DISCUSSION}

Flunarizine, a difluorinated piperazine derivative, is a calcium channel antagonist binding to the dihydropyridine binding site (28). It crosses the blood brain barrier and is relatively selective for the cerebral circulation, having little effect on the heart or systemic vasculature (29). In the present study pretreatment with flunarizine was associated with a dramatic reduction in histologic damage. The acute and chronic behavioral abnormalities were significantly improved.

Two other studies have examined effects of calcium antagonists in immature animals. In 7-d-old rats, subject to the Levine model, $30 \mathrm{mg} / \mathrm{kg}$ of flunarizine limited morphologic injury (20). Our study confirms and extends this result with behavioral measures and more detailed histologic assessment. Improved short term $(2 \mathrm{~h})$ improvement in evoked potentials was found after 10-15 min of cardiac arrest in newborn sheep using $3 \mathrm{mg}$ lidoflazine (21). Unfortunately that study is confounded by the use of multiple other agents including free radical antagonists, short follow-up, and the absence of histologic data.

A range of studies in mature animals suggests that flunarizine is as or more effective than other calcium antagonists in preventing asphyxial damage. Flunarizine but not verapamil is effective in preventing death due to cyanide induced cellular hypoxia in rats (7). Recovery was improved in mice and rats by its administration prehypoxia/anoxia (8) and pre- (9) but not post- (10) cardiac arrest in the dog. In the adult Levine rat, pretreatment with $10-40 \mathrm{mg} / \mathrm{kg}$ of flunarizine reduced parietal neuronal damage (11), whereas only the maximum dose of nicardipine was minimally protective and diltiazem was not (12). In a rat model of partial ischemia, both pre- and postinsult treatment markedly improved histologic outcome in the hippocampus (14), striatum, and cortex (15). In the dog after cardiac arrest, $0.1 \mathrm{mg} / \mathrm{kg}$ intravenously reduced neuronal death only in the hippocampus suggesting that higher doses may be needed for cortical protection (16).

The most direct explanation for the overall neuroprotective action of flunarizine is inhibition of calcium uptake by neurones. Both enhanced excitatory neurotransmitter activity and depolarization due to energy failure favor excessive calcium entry, which in turn may activate a series of damaging events such as protein and phospholipid degeneration and release of ecosanoids and kinins, leading to delayed neuronal death $(3,4)$. Calcium ionophores, by promoting calcium entry produce neuronal death (30), whereas calcium free media are protective (4). Flunarizine inhibits depolarization induced uptake of $\mathrm{Ca}^{++}$into rat synaptosomes in vitro (31) and delays the fall in extracellular $\mathrm{Ca}^{++}$in the hypoxic rat brain (32).

The overall histopathologic pattern of damage in the controls corresponds with the territory of the middle cerebral artery (33): damage appears to be localized primarily by a preferential fall in middle cerebral artery perfusion on the ligated side during hypoxia $(24,34)$. In the infant Levine rat blood flow is dramatically reduced on the ligated side $4 \mathrm{~h}$ after ligation but not $24 \mathrm{~h}$ later, suggesting rapid development of physiologic shunting (34). Flunarizine that enhances and prolongs reactive hyperemia during hypoxia (35) might accelerate this process, maintaining blood flow during the insult. As well it has a protective effect on endothelium (36), and prevented secondary expansion of cerebral thrombosis in rats (13).

Other possible mechanisms have been suggested. As with other calcium antagonists, flunarizine is an anticonvulsant $(29,38)$ and it has been reported to increase levels of the inhibitory purine adenosine by affecting re-uptake (38). Adenosine reduces neuronal hyperexcitability, and may be an endogenous anticonvul- sant (39). Seizures may aggravate cerebral damage induced by asphyxia $(40,41)$. The effective anticonvulsant dose in rats is similar to that used in this study where the flunarizine-treated rats had significantly less posthypoxic fitting than the controls.

The behavioral changes seen here of transient abnormal turning, impaired righting, fits and residual hemiparesis, are similar to those documented in adult rats $(25,27)$. In contrast in $7-d$ old rats subjected to the Levine model, only trivial behavioral abnormalities can be identified $(23,42)$, most likely due to the rapid resolution of acute behavioral disturbances and the delay before the acquisition of motor skills.

The perinatal period is one situation where it is possible to predict likely episodes of asphyxia. Thus antepartum prophylaxis using calcium channel antagonists may be a potential therapeutic approach (43). However, considerable experimental investigation of the safety of such an approach will be required before therapeutic trials are considered.

\section{REFERENCES}

1. Freeman JM (ed) Prenatal and perinatal factors associated with brain disorders NIH Pub 85-1149, Bethesda, MD, pp 237-262

2. Hill A, Volpe JJ 1982 Hypoxic-Ischaemic Brain Injury in the Newborn. Semin Perinatol 6:25-41

3. Siesjo BK 1981 Cell damage in the brain: a speculative synthesis. $\mathfrak{J}$ Cereb Blood Flow Metab 1:155-185

4. Rothman SM, Olney JW 1987 Excitotoxicity and the NMDA receptor. Trends Neurosci 10:299-302

5. Wauquier A, Franson J, Clinicke G 1985 Calcium entry blockers as cerebral protecting agents. In: Godfraind T (ed) Calcium Entry Blockers and Tissue Protection. Raven Press, New York, 163-172

6. Ashton D 1985 Post-hypoxic recovery of synaptic activity in area CA1 of the hippocampus in vitro is improved by in vivo pretreatment with flunarizine. J Neurol 232(suppl): 128

7. Dubinsky B, Sierchio JN, Temple DE, Ritchie DM 1984 Flunarizine and Verapamil: effects on central nervous system and peripheral consequences of cytotoxic hypoxia in rats. Life Sci 34:1299-1306

8. Karasawa A, Kumada Y, Yanada K, Shuto K, Nakamizo N 1982 Protective effect of flunarizine against cerebral hypoxia-anoxia in mice and rats. $J$ Pharmacobiodyn 5:295-300

9. Edmonds HL, Wauquier A, Melis W, Van den Broeck WAE, Van Loon J, Janssen PAJ 1985 Improved short term neurological recovery with flunarizine in a canine model of cardiac arrest. Am J Emerg Med 3:150-155

10. Newberg LA, Steen PA, Milde JH, Michenfelder JD 1984 Failure of Flunarizine to improve cerebral blood flow or neurologic recovery in a canine model of complete cerebral ischemia. Stroke 15:666-671

11. Van Reempts J, Borgers M, Van Dael L, Van Eyndhoven J, Van de Ven M 1983 Protection with flunarizine against Hypoxic-ischaemic damage of the rat cerebral cortex. A quantitative morphologic assessment. Arch Int Pharmacodyn 262:76-88

12. Van Reempts J, Borgers M 1985 Ischemic brain injury and cell calcium: morphologic and therapeutic aspects. Ann Emerg Med 14:736-742

13. Van Reempts J, Van Deuren B, Van de Ven M, Cornelissen F, and Borgers M 1987 Flunarizine reduces cerebral infarct size after photochemically induced thrombosis in spontaneously hypertensive rats. Stroke 18:1113-1119

14. Deshpande JK, Wieloch T 1985 Amelioration of brain damage following post ischemic treatment with flunarizine. Neurol Res 7:27-29

15. Deshpande JK, Wieloch T 1986 Flunarizine, a calcium entry blocker, ameliorates ischemic brain damage in the rat. Anesthesiology 64:215-224

16. Kusum K, Krause G, Koestner A, Hoenner T, White B 1987 Effect of flunarizine on global brain ischemia in the dog: a quantitative morphological assessment. Exp Neurol 97:115-127

17. White BC, Gadzinski DS, Hoehner PJ, White JD, Trombley JH 1982 Effect of flunarizine on canine cerebral cortical blood flow and vascular resistance post cardiac arrest. Ann Emerg Med 11:119-126

18. Grotta JC, Pettigrew LC, Rosenbaum D, Reid C, Rhoades H, McCandless D 1988 Efficacy and mechanism of action of a calcium channel blocker after global cerebral ischemia in rats. Stroke 19:447-454

19. Vibulsreth S, Dietrich D, Busto R, Ginsberg MD 1987 Failure of nimodipine to prevent ischemic neuronal damage in rats. Stroke 18:210-216

20. Silverstein FS, Buchanan K, Hudson C, Johnston MV 1986 Flunarazine limits hypoxic-ischaemia induced morphologic injury in immature rat brain. Stroke 17:477-482

21. Thiringer K, Hrbek Z, Karlsson K, Rosen KG, Kjellmer I 1987 Postasphyxia cerebral survival in newborn sheep after treatment with oxygen free radical scavengers and a calcium antagonist. Pediatr Res 22:62-67

22. Levine $S 1960$ Anoxic encephalopathy in rats. Am J Pathol 36:1-17

23. Rice JE, Vannucci RC, Brierley JB 1981 The influence of immaturity on hypoxic-ischemic brain damage in the rat. Ann Neurol 9:131-141

24. Vannucci RC, Lyons DT, Vasta F 1988 Regional cerebral blood flow during hypoxia-ischemia in immature rats. Stroke 19:245-250

25. Levy DE, Brierley JB 1975 Brief hypoxia-ischemic initially damages cerebral 
neurones. Arch Neurol 32:450-456

26. Smith ML. Auer RN, Siesjo BK 1984 The density and distribution of ischemic brain injury in the rat following 2-10 min of forebrain ischemia. Ann Neuropathol 64:319-332

27. Brown AW, Brierley JB 1971 Anoxic-ischaemic cell change in rat brain light microscopic and fine structural observations. J Neurol Sci 16:59-84

28. Borgers M, DeClerck F, Van Reempts J, Xhonneux R, Van Nueten J 1984 Selective blockade of cellular calcium overload by flunarizine. Int Angiol $3: 25-31$

29. Holmes B, Brogden RN, Heel RC, Speight TM, Avery GS 1984 Flunarizine: a review of its pharmacodynamic and pharmacokinetic properties and therapeutic use. Drugs 27:6-44

30. Lehmann A 1987 Neurotoxicity of calcium ionophore A23187 in immature rat cerebellar slices. Neurosci Lett 79-263

31. Wibo M, Delfosse I, Godfraind T, 1983 Action of flunarizine and cinnarizine on calcium fluxes in synaptosomal preparations from rat cerebral cortex. Arch Int Pharmacodyn Ther 263:333-334

32. Holler M, Dierking H, Dengler K, Tegtmeyer F, Peters T, 1986 Effect of flunarizine on extracellular ion concentration in the rat brain under hypoxia and ischemia. In: Battistine N, Courbier R, Fiorani P, Plum F, Fieschi C (eds) Acute Brain Ischemia, Medical and Surgical Therapy. Raven Press, New York, pp 229-236

33. Tyson GW, Teasdale GM, Graham DI, McCulloch J 1984 Focal cerebral ischemia in the rat: topography of hemodynamic and histopathological changes. Ann Neurol 15:559-564
34. Dwyer BE, Nishimura RN, Fujikawa DG 1988 Cerebral hypoxia-ischemia in immature rats: methodologic considerations. Exp Neurol 99:772-777

35. Phillis JW, Delong RE, Towner JK 1985 The effects of lidoflazine and flunarizine on cerebral reactive hyperemia. Eur J Pharmacol 112:323-329

36. DeClerck F, Loots W, Somers X, Van Gorp L, Verheyen A, Wouters L 1985 Thromboxane A2-induced vascular endothelial cell damage and respiratory smooth muscle cell contraction: inhibition by flunarizine, a calcium overload blocker. Arch Int Pharmacodyn Ther 274:4-23

37. DeSarro GB, Meldrum BS, Nistico G 1988 Anticonvulsant effects of some calcium entry blockers in DBA/2 mice. Br J Pharmacol 93:247-256

38. Phillis JW, Wu PH, Coffin VL 1983 Inhibition of adenosine uptake into rat brain synaptosomes by prostaglandins, benzodiazepines and other centrally active compounds. Gen Pharmacol 14:475

39. Dragunow M 1986 Endogenous anticonvulsant substances. Neurosci Biobehav Rev 10:229-244P

40. Westerlain CG, Plum F 1973 Vulnerability of developing brain to electroconvulsive seizures. Arch Neurol 29:38-45

41. Siesjo BK 1986 Cellular calcium metabolism, seizures and ischemia. Mayo Clin Proc 61:299-302

42. Young RSW, Kolonichi J, Woods CL, Yagel SK 1986 Behavioral performance of rats following neonatal hypoxia-ischemia. Stroke 17:1313-1316

43. Gluckman P, Gunn A, Williams C, Cook C, Bennet L 1988 Neural function in the ovine fetus-the impact of asphyxia. In: Gluckman P, Johnston B, Nathanielsz P (eds) Advances in Fetal Physiology: Review in Honor of G. C. Liggins. Perinatology Press, Ithaca, NY (in press) 